\title{
Cultural Factors in the Flow of International News: A Review of the Literature
}

\author{
Takuya Sakurai ${ }^{1, *}$ \\ ${ }^{1}$ Tokyo Denki University, 5 Senju-asahi-cho, Adachi, Tokyo 1208551, Japan
}

\begin{abstract}
This paper offers a review of the literature of international news flow, and surveys how the previous studies have attempted to capture "cultural factors" influencing the flow. The factors are grouped into four types of variables: language, former colonial tie, ethnicity, and geographical proximity. This paper argues that cultural factors cannot be significant without economic interests in the era of post-Cold War, that the structure of international news is imbalanced because a few powerful countries dominate the international news market, and that international news reduces cultural varieties to the singular international realities disseminated by the media of such countries.
\end{abstract}

\section{Introduction}

Our images of globalization are mostly mediated through many institutions such as science, education, and the media [1]. Few people understand how much the world is globalized directly. Instead, most people rely largely on international news, one of the most effective and useful media to know how the world is getting globalized. International communication studies have attempted to examine international news since the inception of the New World Information and Communication Order (NWICO) in the late 1960s [2]. Against the backdrop of the United Nations Educational Science and Cultural Organization (UNESCO), the studies have begun to indicate that the structure of international news flow is imbalanced [3], and that news from developing countries is often biased and misrepresented [4]. A number of studies have also investigated the determinants of international news flow, especially since Scandinavian scholars such as Galtung and Ruge [5] and Ostgaard [6] proposed theoretical foundations that focus on "factors" influencing the flow of international news. The studies have proposed various factors influencing international news flow and attempted to identify what the best factors are to predict the flow of international news.

As factors influencing the flow, cultural affinity and cultural proximity are believed to be able to predict and describe how some international news is selected over others. They basically assume that if a guest country is culturally closer to a host country, the host country's media cover the guest country more often than those countries that are culturally less close. The factors demonstrate that the flow of international news help Western country locate at the center of the process to select international news, and that the culturally closer

*Corresponding author: tsakurai@cck.dendai.ac.jp 
countries are to those Western countries, the more likely they are selected. They are also believed as one of the factors that reveal the dominance of Anglo-Saxon and the imbalance between Western developed countries and non-Western developing countries in the flow of international news. This paper thus intends to summarize and explain how cultural aspects of the flow of international news have been studied and to reveal some underpinning elements of the studies. More specifically, it is our task to recap how culture is conceptualized and operationalized in the flow of international news and to unfold what is assumed behind the idea of "culture" in the studies.

\section{Cultural Factors: A Review of the Literature}

There are roughly two types of factors that influence the flow of international news: intrinsic (event-oriented) and extrinsic (context-oriented). The former refers to newsworthiness of events such as importance, sensationalism, prominence, conflict, negativity, timeliness, and proximity [7-8]. The event-oriented approach examines news values intrinsic in the news itself. In other words, news values of events are considered to determine what news to be selected over others. The latter mentions extra-media components such as political and economic elements, population, geographical proximity, cultural proximity, and press freedom. The context-oriented approach examines how extrinsic predictors influence news coverage among countries. The following components are usually used as extra-media variables: communication access and technologies [9], cultural proximity [6], economic development [10], elite status [11], former colonial ties [12], ideological groupings [13], international news services [14], geographical proximity [15], GNP per capita [16], language [17], population and size of nation [18], and regionalism [19].

The previous studies have operationalized cultural factors as cultural proximity and/or affinity. Some of them employ cultural factors as an independent determinant influencing international news flow. Others tend to employ cultural factors as a determinant interrelated with other determinants influencing international news flow. The former attempts to see how well cultural factors predict international news while the latter evaluates what role cultural factors play in determining international news flow. Hester [20] argues that cultural affinity involves language, migration, travel, and former colonial relations between countries. Language is employed to evaluate how cultural affinity works in international news flow [17-18], while language is also used to assess cultural proximity in the research on international news flow [7-21] Cultural affinity, furthermore, is measured in terms of ethnicity [8-22], former colonial relationships [12-19], or geographical proximity [23]. Cultural proximity is also evaluated by some concepts such as ethnicity $[5,24,25,26]$ and geographical proximity [6]. While those usages and definitions of cultural factors vary across the studies, the cultural factors employed in the previous studies can be categorized into the following four groups according to how they are conceptualized and operationalized under the names of either proximity or affinity: language, colonial tie, ethnicity, and geography.

\subsection{Language}

Language is employed as a component of cultural factors influencing international news flow. Wu [4-27] hypothesizes, if a common language is shared between a guest country and a host country, the host country's media cover the guest country more often than those countries that do not share the language. Kim and Barnett [18] employed language as a means of capturing how cultural affinity influenced international news flow and of predicting the structure of international news flow. They propose that the world should be 
divided into the following eight geographical-linguistic groups in terms of what language they use: "European-North American, Chinese, Portuguese, Greek-Tuck, Latin AmericanSpanish, Middle Asian-Indian, North African, and overseas French groups” (p. 346).

While Kim and Barnett's and Wu's [4-18] studies employed language to examine international news flow in the larger framework of global news system, Chang, Shoemaker, and Brendlinger [7] used it to identify the best predictor determining what international events were covered in the U.S. media. Kariel and Rosenvall [17] employed language to compare English and French newspapers in Canada as to see how cultural affinity influences international news natures. Comparing two types of Canadian daily newspapers, English and French newspapers, Kariel and Rosenvall [17] found that both the newspapers used the same international news sources from the Canadian press. While Kim and Barnett [18] argue that language comes within the context of geographical proximity, Kariel and Rosenvall [17] mention that each newspaper tended to choose what international news to print in terms of certain cultural affinities of its readers. French newspapers tended to choose news items from France, whereas English newspapers those from the United Kingdom.

\subsection{Colonial Tie}

While language is a powerful tool when modern nation states unify territories and when a country colonizes other countries, former colonial tie itself is also considered to be an important factor influencing international news flow [12]. Dupree [10] argues that the best predictors of international news are former colonial ties and economic comparative figures. Robinson and Sparkes [11] discuss that both the United States and Canada sent a large number of foreign correspondents to England. Mayer indicates that the former British colonies obtain their international news from the British wire services and the former French colonies used those from the French wire services. Former colonial tie is also closely related to technological investment and presence of international news agencies. Since it is much more economical to use news copies provided by news services than to send correspondents to foreign countries, the presence and the size of news agencies stationed in a former colonized country were important in determining the amount of international news on that country [28]. In the study of international news in cyberspace, Kang and Choi [29] unveiled that the inequity in the structure of international news flow should be interpreted as technological dependency. The technological resources that could make the distribution of information possible were available to only the limited developed powerful nations. Hicks and Gordon [30] also argue that television coverage of international events was more likely controlled by technological problems such as availability of camera crew and cost of transmission of stories than actual geographical proximities.

In a comparison of the directions and volumes of news exchanges between Canada and the United States, however, Robinson and Sparkes [11] found few technological differences between the two countries. In order to explain a huge imbalance between the two countries in terms of being international news, the presence of international news agencies could be considered to be the largest factor. The global news wire services such as AP and UPI, Agence France-Press, and Reuters dominate international news market as wholesalers, selling their products to ninety agencies in the United States and Canada [11]. Mayer [13] also points out that the Big Four international news agencies - AP, UPI, AFP, and Reutercontrol "the bulk of international news" from the perspective of neoimperialism in global news flow (p. 256). The dominance of the Big Four news syndicates allows the United States, France, and the Great Britain to carve out their hegemonic spheres of international 
influence. In a similar sense, Masmoudi [2] argues that the influence of the "Big Four" Western news agencies is the major problem of the imbalances in international news flows.

\subsection{Ethnicity}

Ethnicity explains how immigrants affect cultural factors influencing international news flow and coverage. Golan and Wanta [22] counted the numbers of immigrants in the United States from different foreign countries as an indicator of cultural affinity. Johnson [25] examined the quantity of U.S. newspaper coverage of Mexico to understand how Mexican immigrants affected the amount of international news on U.S. newspapers. She found that, although cultural proximity affected the selection of foreign news, it did not play a main role in deciding to cover the subject. Zaharopoulos [8] investigated the Greek coverage of the 1988 U.S. presidential campaign to examine whether the Greek media would find cultural proximity in one of the candidate, the son of Greek emigrants. The study concludes that the local gatekeepers had control in selecting some news over others on the coverage of the 1998 U.S. presidential election campaign, recognizing that cultural proximity played an important role in the way two major Greek newspapers covered the campaign.

While many studies have conducted content analysis to examine cultural factors, a few studies interview journalists to see how cultural proximity influences journalists' decisions of selecting some international news over others with regard to their personal and professional backgrounds [24-26], for example, interviewed AP Interbureau wire editors and Wisconsin newspaper wire editors. The Interbureau editors believed their clients to be "more interested in news from foreign nations which share common cultural and ethnic backgrounds with the United States" and stated that "they would give first priority to stories from developed Anglo-Saxon nations over items from non-Anglo-Saxon developing countries if news values were held constant (p. 37).

\subsection{Geographical Proximity}

Some studies have attempted to conceptualize cultural proximity in a geographical sense and to propose geographical proximity as one of main factors influencing international new flow. While Kim and Barnett [18] employed language as a measurement of cultural affinity, the study also shows that language cannot be considered without the context of geographical proximity. Ostgaard [6] did not set up a clear boundary between cultural and geographical proximities. He argues that cultural proximity has more influence on news flow than geographic distance because "for whatever reason the news is published, it will be intended to reach an audience" (p. 25). Wang [23] used cultural affinity as one of the factors determining international news on the foreign countries' coverage of the 1989 Chinese student pro-democracy movement. Her study shows that neither cultural affinity nor geographical proximity necessarily affected the extent and the direction of the coverage as much as the political ideology and diplomatic sensitivity did. Meyer [13] advocates the concept of "news dependency" (p. 243), which explains how developing countries are dependent upon the West for international news. Almost half of international news in the Latin American newspapers was sent from the American news agencies (AP and UPI).

\section{Discussion and Summary}

Galtung and Ruge [5] developed cultural factors as psychological aspects of international news - how audience perceived international realities. They were originally concerned with how audiences could find their interests in international news; therefore, they 
conceptualized some sort of familiarity that audiences might find in foreign countries as cultural factors. These factors, however, cannot be the best predictors of international news flow when they are examined with other factors such as political and economic factors [4, 19, 27]. Therefore, Rosengren [31] added extra-media (context-oriented) factors such as political and economic variables to the Galtung and Ruge's intra-media (event-oriented) factors [5]. Once cultural factors were widely identified as one of extra-media factors, the studies began to seek more comparative and testable variable to examine cultural factors. Methodologically, the studies have reduced cultures to the terms either proximity or affinity first, and examined the flow of international news through language, colonial tie, ethnicity, and geographical proximity. Not only does this kind of operationalization, however, reduce diversified cultures around the world to distinguishable and testable accounts, but also it incorporates cultural differences into the singularly comparative perspective. The singular perspective reduces cultural differences to some elements that support the values and norms of a few powerful countries, such as politics, economy, trade, power relationships. Thus, the following conclusions are made: No factors can be as influential as political ideology on global political coverage [23], factors of presence of international news agencies are more crucial element of news gathering [4-28], and economic interests play significant roles in international news flow [4]. Wu [27] indicates that economic interactions between countries are important to be covered because economic interests produce more coverage such as politics and culture in foreign media. Ishii [16] also argues that since cultural factors always contain economic and political implications, the flow of international news is much about how the international establishments sharp and disseminate their powers over the world.

As part of international communications, thus, international news plays significant roles in promoting and supporting Western cultural values. Relationships between countries are reduced to a comparative "economy" paradigm, and cultural realities are being integrated into economy-centered perspective. According to $\mathrm{Wu}$ [4], one of the reasons why economic factors are the best predictor of international news flow is that economy tends present a country rather than ideological and/or political orientations on the era of the post-Cold War. In a similar sense, Wasburn [32] describes the post-Cold War world as an international circumstance where "power depends as much on the ability of a nation's banks and corporations to capture market share and defeat foreign trade rivals as it does on the capabilities of its military power" (p. 191). This economy-centered tendency in the flow of international news is the result of justifying the Westernized market expansion. Even though the studies identify the imbalances among between Western and non-Western countries as the problems to be minimized, international news itself is a product of the global market; in other words, international news both supports the market and is part of the market. International news is a commercial product and is selected to meet the needs of customers (audience and advertisers), and cultural factors thus tend to be reduced to economic interests. Seeing international news as "a commodity" or "a cultural artifact" enables us to understand how the media disseminate those globalized realities [18]. Interestingly, this nature of international news flow still remains in Internet news services [33] and social media networks [34], while the latter notes that there emerges some divergence in the specific news events that gather attention. Accordingly, future studies need to examine if the idea of "culture" has remained or changed in the flow of international news with the Internet.

In sum, we have reviewed the literature of international news flow and found that cultural proximity and affinity are examined through language, colonial tie, ethnicity, and geographical proximity. As seen above, in the flow of international news, while powerful countries play central roles, less powerful countries have to accept the power structure of international news as marginalized group. Although the flow of international news presents itself as a "gatekeeper" model [35], selection is a construction as well. Selecting some 
international news over others is based on how media construct news as social artifacts in order to reflect and reinforce the international establishment's status quo. Frequency to be covered in international news just encourages many countries to join the competition where a few Western powerful countries set up the rules. Guest foreign cultures within the singular perspective have to be compared quantitatively and seen in the scope that one is "better" than another. This legitimates the "one-way flow" from a tiny rich group to the rest of the vast majority and requires the majority to see the world that way the flow does. International news thus plays a significant role in constructing certain globalized realities centralizing a few powerful countries [4-36]. As Mattelart [37] insists, an emerging international network of information and communication might bring not a fragmentation of the world, but a uniform world culture.

\section{References}

1. J.V. Ginneken, Understanding global news: A critical introduction. (Sage, Thousand Oaks, CA, 1998)

2. M. Masmoudi, Journal of Communication, 29 (1979)

3. R.L. Stevenson, Journalism Quarterly, 69, 3 (1992)

4. H.D. Wu, Journal of Communication, $\mathbf{5 0}$ (2000)

5. J. Galtung, H. Ruge, Journal of Peace Research, 2 (1965)

6. E. Ostgaard, Journal of Peace Research, 2 (1965)

7. T. Chang, Shoemaker, P. J., \& Brenlinger, N. Communication Research, 14 (1987)

8. T. Zaharopoulos, Journalism Quarterly, 67 (1990)

9. A.J. de Verneil, A correlation analysis of international newspaper coverage and international economic, communication and demographic relationships. (Transaction, New Brunswick, NJ 1977)

10. J.D. Dupree, International Communication Gazette. 17 (1971)

11. G.J. Robinson, V.M. Sparkes, International Communication Gazette, 22 (1976)

12. T. Nnaemeka, J. Richstad, International Communication Gazette, 26 (1980)

13. W.H. Meyer, Comparative Political Studies, 22 (1989)

14. J.F. Larson, Journal of Communication, 29 (1979)

15. H.D. Wu, International Communication Gazette, 60 (1998)

16. K. Ishii, Gazette Leiden then Deventer then Dordrecht, 57 (1996)

17. H.G. Kariel, L.A. Rosenvall, Journalism Quarterly, 59 (1983)

18. K. Kim, G.A. Barnett, Communication Research, 23 (1996)

19. W.A.E. Skurnik, International Communication Gazette, 28 (1981)

20. A. Hester, International Communication Gazette, 19, (1973)

21. Y. Chang, K. Chang, International Communication Bulletin, 38, (2003).

22. G. Golan, W. Wanta, International Communication Gazette, 65, (2003)

23. S. Wang, International Communication Gazette, 49 (1992)

24. A. Hester, International Communication Gazette, 17 (1971)

25. M.A. Johnson, Journalism and Mass Communication Quarterly, 74 (1997)

26. S. Peterson, Journalism Quarterly, 58 (1979)

27. H.D. Wu, International Communication Gazette, 65 (2003)

28. T.J. Ahern, Jr. (1984). Determinants of foreign coverage in U.S. newspapers. In R. L. Stevenson \& D. L. Show (Eds.), Foreign news and the new world information order (Iowa State University Press, Ames, 1984)

29. N. Kang, J.H. Choi, Communication Research, 26 (1999)

30. R.G. Hicks, A. Gordon, Journalism Quarterly, 51 (1974)

31. K.E. Rosengren, Journal of Peace Research, 11 (1974)

32. P.C. Wasburn, Political Communication, 14 (1997) 
33. T.K. Chang, I. Himelboim, D. Dong, International Communication Gazette, 71, (2009)

34. N.T. Ekeanyanwu, Y. Kalyango, A.S. Peters, European Scientific Journal, 8, (2014)

35. D.M. White, Journalism Quarterly, 27 (1950)

36. H.W. Park, Journal of Communication, 48 (1998)

37. A. Mattelart, Mapping world communication: War, progress, culture, (University of Minnesota Press, Minneapolis, 1994) 